\title{
Research and Practice on the Teaching Reform of Database Course
}

\author{
Jingmin Wang \\ Department of Economic Management \\ North China Electric Power University \\ Baoding, China \\ jingminwang126@126.com
}

\author{
Haoli Chen \\ Department of Economic Management \\ North China Electric Power University \\ Baoding, China \\ chenhaoli.1989@163.com
}

\begin{abstract}
Database technology is one of the core technologies in information technology. Cultivating high-quality information professionals makes database course essential .Combining with the teaching practice, this paper, from teaching content, teaching methods, assessment modes and other aspects, makes an comprehensive study in database course reform on the basis of the drawbacks of the traditional database course, which takes knowledge system as the core.
\end{abstract}

Keywords- database course; teaching reform; methods and means; assessment mode

\section{INTRODUCTION}

As the basis technology in the information field, database technology has formed a relatively complete theoretical system and produces a large number of practical systems after decades of development, and nearly $80 \%$ of the entire computer applications relates to database technology application. Moreover, the development of network communication technology and the demand of knowledge mining have opened up a new broader prospect for database technology, ushering in a faster and stronger development momentum. Visibly, database and its technology is the premise of information resources management, exploitation and utilization in the information society [1]. Therefore, the "database principle and application" course opened by all the colleges and universities has become a very important basic professional course, shouldering the task to cultivate students' theoretical and practical knowledge of database. Database course' teachers concern that how to train database technology personnel to meet the needs of society. Aiming at a series of drawbacks in the traditional database course, such as unreasonable teaching contents, outdated teaching methods, single teaching materials and unappreciated teaching staff, and combined with the problems encountered in database teaching practice of North China Electric Power University, this paper proposes a new database teaching reform idea and shows series of reform measures combined with the practice of reform.

\section{The Status And Problems Of Database Teaching}

Currently, the teaching of traditional database theory and application is generally more emphasis on database theory. Teaching is not from how to use a database management system to solve practical problems, but basically starts from a database's own system, resulting in lack of students' training on database program design capability and operational ability, let alone guide students to research and explore [2].

Combined with the teaching practice, the author summarizes the mainly problems in teaching of the traditional database theory and application which are as follows:

\section{A. The Teaching Purpose Is Unclear, the Teaching Content Is Unreasonable, and the Theory Is Unrealistic}

For different professional levels of students, should we train an operator who only knows to operate simple commands, or train an user that has a certain system development ability? The unclear teaching purpose has the results that the curriculum lacks systematic and the first follow-up courses in the professional curriculum are not clear.

Lacking the contents and practice associated with the major' main courses, teaching content is too generalized and do not highlight the differences of different majors in the curriculum requirements. For example, you can increase the embedded SQL language theory hours to make a preparation for mastering database application system development software better in the database contents of information management major, you can also increase the database security, database recovery techniques and concurrency control system aspects for computer major.

\section{B. The Teaching Method Is Outdated and does Not Pay Attention to the Combination of Theory and Practice}

The template is used to format your paper and style the text. All At present, the database course materials are basically organized and arranged according to teaching contents and the sequence of knowledge system: The first part focuses on the basic theory of Database; latter focuses on specific database management system software. Teachers often used the past and simple "teach $\rightarrow$ Example $\rightarrow$ job" type of teaching methods in teaching. They often first introduced purely theoretical knowledge, and then to explain the specific use of a database management system according to the order of arranged textbooks. They first systematically introduced the theoretical knowledge and command, and then to give the corresponding examples according to the theoretical knowledge and command. The teacher's focus is on the knowledge to their students, rather than the application methods of knowledge and skills to their 
students in this kind of classroom teaching, which takes knowledge as the core. As a consequence, there are the following problems: First, when students are learning theories in the first half, they can not really understand when to use these theories and how to use them, so generally students feel the theories are too abstract and difficult to understand, and they are unable to lift the learning interest. When they study a specific database management system in the latter, they only master software to use and operate simply because they do not know the actual purpose. Therefore, students just master a few isolated knowledge and a software' basic operation after finishing the course, and they can not design and develop a specific database system and complete the scheduled teaching purpose. Secondly, the classroom teaching which takes knowledge systems as the core must take integrity of knowledge systems into consideration in the organization of teaching contents, so it inevitably needs to introduce many theories without guiding significance to the practice. So the theoretical teaching likely guides students to accept the knowledge rather than apply the knowledge.

In addition, the current teaching methods make teachers as the center and give priority to the course and theory rather than the practice [3]. Although syllabus arranges a certain period of hours for the computer experiment, it only takes the computer as a means of validation theory; in practice it has been unable to meet the teaching requirements of modern databases.

\section{Curriculum Assessment Mode is not Conducive to Examine Students' Practical Skills}

Assessment is an effective and important way to test the teaching effectiveness, and it plays an important guiding role in learning and teaching, different assessment methods have different effects on students' learning motivation. Currently, database assessment methods generally combine theory test with report on computer experiments to examine students' course learning. Theory examination mostly focuses on the assessment of theoretical knowledge, they can not link theory with practice well, and they certainly can not do database analysis, design and development independently aiming at specific problems, so it makes students feel boring and abstract for the theoretical study, students have to deal with the examination by rote- learning and after the examination theoretical knowledge are forgotten quickly; Computer experiment examination means to give students some small computer questions to practice, finally to form a computer experiment report. Although it has some practical operability, each operation items are independent and they only pay attention to the computer operation skill of assess knowledge. Basically the answer was fixed in several methods. Many students copy other classmates' experiment report at the end of the course and the vast majority of submitted experiment reports are identical. It is necessary to reform the assessment methods, because they all have certain limitations and suppress students' enthusiasm in active learning.

\section{TEACHING REFORM IDEAS OF DATABASE COURSE}

Based on years of teaching practice in database course, the author' ideas in database course reform are as follows: First of all, we should make a clear teaching goal, clarify the teaching requirements of different professional levels, develop a reasonable teaching content , and teach students in accordance of their aptitude. Second, we should improve teaching methods and means, foster the idea of people-oriented, pay attention to the interaction between teachers and students in the teaching process, and mobilize students' enthusiasm about learning, so that students can change from accepting knowledge passively to searching for knowledge actively, as well as we should focus on the cultivation of students' innovative ability. Once more, we should pay attention to the theory with practice, combine theory with practice closely in the teaching process, absorb and sublimate the theory knowledge by practice. Finally, we should attach great importance to the course assessment and change the traditional pure theory test to the double-track assessment of theory and practice.

\section{Specific Reform Measures Of Database Course}

\section{A. Refine the Teaching Content; Make It Meet the Actual Needs}

With the popularity and wide application of information technology, company has a growing demand for using the database of college students. In teaching we should try to make the teaching content constantly updated in order that teaching content can adapt to the development of disciplines and meet the demand of company's practical application. In the teaching process of database, the school not only should be based on different levels and different professional orientations and student employment orientations to determine the corresponding teaching goals and requirements, but also select the corresponding teaching content according to different requirements of different levels and different professional in database master degree. Such as information management professional original give priority to Visual FoxPro database management system in application part, and now began to focus on SQL Server and Oracle applications; financial professional can add part of the knowledge of SQL Server appropriately on the basis of Visual FoxPro or Access to meet the society' needs.

\section{B. Improve the Teaching Mode, Enhance Teaching Methods}

We can use the teaching method, which takes the case as the core, to reform the teaching mode. Compared with the traditional teaching of knowledge system, theory course is not based on the order of the teaching material to introduce knowledge points, but introduce the relevant knowledge points around the case. First introduce the application background of the case and make a straightforward functional analysis to guide students to discover problems, and then introduce the waned theoretical knowledge to solve the problem, again with the students analyze and solve the problem by using their theoretical knowledge, finally let the students design another similar example independently after class to use in the experimental class. Teachers must skillfully reflect the guiding significance knowledge to practice which are introduced in the teaching material on the teaching case as much as possible in designing teaching plans, so it is usually not only to introduce a case from beginning to end, the introduction of some knowledge points also must be interspersed with fragments of 
other cases[4]. Thus, the purpose of case teaching is not only to introduce students the knowledge, more importantly, it is to cultivate students' application ability for new knowledge by guiding students to apply knowledge to the case.

In terms of teaching methods, use the "multimedia, live demonstrations" as the main way to make classroom teaching and practical teaching combined. Teachers lead students to practice and give some explanations at the same time through the use of software in the classroom to achieve a live demonstration of the entire process, to fully mobilize students' learning enthusiasm and initiative, to give students a more profound impression, to enhance students' perceptual understanding for knowledge, as well as to truly reflect the combination of theory and practice.

\section{Strengthen the Practice}

The database is an extremely practical course[5]. Computer operation can help students understand and digest the theoretical knowledge in the class and the effect of the computer operation directly affect the teaching effect, so practice is particularly important for learning the database. We should strengthen the training of the experiment link in teaching and pay attention to cultivate students' team consciousness and creative ability.

First, we must make a reasonable arrangement on the computer experiment class, synchronize the computer experiments with the theoretical teaching, especially about the time and the content. So it requires teachers to design the content of computer experiments according to the progress of the course content before class and write the experiment instruction with examples and exercises, the content of which should stick to the teaching material. Second, we must ensure the effect of the practice and make the purposes and steps of computer experiments clear. Students should operate computers according to the requirements of the computer experimental instruction. Teachers should make timely guidance about the complicated problems students encountered in the process of computer practice and make a public explanation for the general problems existed in the experiment. Computer guidance should be a good time to intensively solve the problems that are not easy to find in the theory teaching; meanwhile it is a good place to introduce typical programming methods and intensively improve students' programming ability. Students should submit reports after the experiments, requiring students to write the experiment purpose, experiment contents, experiment steps and the experience, feelings and problems encountered in the process of experiments in the experiment reports. Teachers should carefully scrutinize and timely comment and guide. Finally, divide the students into groups to make each group learn a division of labor. They are required in an RDBMS to develop a small database application system for a department or unit by using the appropriate application system development tools, show the detailed design report of various stages in database design, write the system's main functions and instructions, submit the running system, and write out the harvest and experience, resolved and unresolved issues, further perfect suggestions and ideas. In brief, through the job of database design and application development, we can promote students to master the course concepts, knowledge and technology and train students' system thinking, innovation spirit, practice ability and the sense of teamwork in the process of system design and development.

\section{Reform the Assessment Mode of the Course}

Database theory and application is a course which combined the theory with practice closely. If only use the traditional evaluation methods of theory test, it will cause students to cope with examination and memorize the relevant theoretical knowledge by rote and without understanding, usually do not learn and think seriously, make a temporary assault before examination, thus a phenomenon that they can not apply the theory will appear. It is contrary to the goal that trains applied talents [6].

The assessment of practical part should be increased for database assessment mode, and we can not only assess students' practice according to students' completion conditions in computer experiment reports. Computer experiment report cannot reflect students' actual programming skills and the ability to solve application problems objectively. Adopting the "quiz + exam" mode means that add quiz testing session in the usual computer experiment, make a assessment for the key elements and key knowledge points students should master on the section of the computer experiment course. Teachers do track record, as part of the total score in the practical assessment scores. After completion of the class of practice, organize students to make a comprehensive exposition, for assessment of students' ability to develop general small database system by synthetically applying the knowledge and skills they have learned.

\section{CONCLUSION}

Database course is a discipline that pays equal attention to the theory and practice. We must conduct a comprehensive reform in the teaching content, teaching methods and means, assessment mode and other aspects, persist in combining theory teaching with practice teaching, and adapt the teaching to practical application. Only in this way, can the database course teaching reform achieve results.

\section{REFERENCES}

[1] Qian Zhongxue. Principle and application of database[M]. Beijing: Beijing University of posts and telecommunications press, 2008:1-2.

[2] Zhong Hui. Exploration and practice of database course teaching reform [J]. Journal of Shenyang architectural university (social science edition), 2010, 12 (3): 379-381.

[3] Hu Xiu. The principle and application of database course teaching reform discussion [J]. Journal of Shayang teachers' college, 2008 (3): 8889.

[4] Tian Feng. Database course teaching reform research [J]. Journal of information science and technology of China, 2008, 10, 184

[5] Wang shan. Database course teaching reform: oriented the 21 st century curriculum and national fine-designed courses $[\mathrm{J}]$. Chinese university education, 2006, 4:14-17

[6] Ye Xia, Li Junshan, Wei Suyuan. Teaching Reform Summary of Database theory and application [J].Journal of Jilin institute of education, 2009, 25 (7): 39-41. 